\title{
Identidad fronteriza en Chihuahua, México, un recorrido del siglo XVII al XXI
}

\author{
Border identity in Chihuahua, Mexico, a journey from \\ the 17 th to the 2 Ist century
}

\section{Guillermo Hernández Orozco* Stefany Liddiard Cárdenas**}

\begin{abstract}
* Profesor investigador de la Universidad Autónoma de Chihuahua (México). Es doctor en Ciencias Pedagógicas por el Instituto Superior Pedagógico Enrique José E. Varona (Cuba). Entre sus publicaciones recientes están: "José Joaquín Calvo López, fundador del Instituto Científico y Literario, hoy Universidad Autónoma de Chihuahua" en IE Revista de Investigación Educativa, Vol. 8, No. I4 (20I7); Debates por la historia (Cinco tomos). Obtuvo el Reconocimiento Eduardo Flores Kastanis a la Investigación Educativa 20I8; cuenta con Perfil Prodep y es miembro del Sistema Nacional de Investigadores, nivel I. Su tema de interés es la historia e historiografía de la educación. Correo electrónico: ghernand@uach.mx

(D) https://orcid.org/oooo-000I-7287-8240

*: Profesora investigadora de la Universidad Pedagógica Nacional del Estado de Chihuahua (México). Es Doctora en Educación, Artes y Humanidades. Entre sus publicaciones recientes están: "La hacienda de Humboldt en Chihuahua, lugar de refugio para los bóers precedentes de Sudáfrica a principios del siglo XX" (2019) en Espacio abierto: cuaderno venezolano de sociología 28 (I), I79-I98. Es socia activa de Red de Investigadores Educativos Chihuahua y de Sociedad Mexicana de la Historia de la Educación. Sus temas de interés son la historia e historiografía de la educación. Correo: stefanyliddiard@gmail.com

(D) https://orcid.org/oooo-0002-3234-4372
\end{abstract}

Historial editorial

Recibido: 24-noviembre-2019

Aceptado: 15-julio-2020

Publicado: 21-julio-2020

ISSN-e: 2594-2956 
Identidad fronteriza en Chihuahua, México, un recorrido del siglo XVII al XXI

\section{Resumen}

En el siguiente artículo se expone un análisis sobre la construcción de la identidad fronteriza en el estado de Chihuahua, haciendo un recorrido desde el siglo XVII hasta el XXI. El trabajo se organiza en varios apartados temáticos con los resultados de una investigación principalmente de archivo. Bajo un enfoque historiográfico crítico y con metodología de corte interpretativo, se conformó un rastreo mediante la recuperación de documentos primarios, útiles para la descripción e interpretación de una serie de sucesos que han impactado y redireccionado esta identidad fronteriza. Como resultado se muestran distintos momentos críticos que han conformado la representación simbólica del término frontera en la población chihuahuense, dentro de su contexto de pluralidad ideológica, étnica, geográfica y cultural.

Palabras Clave: historia, historiografía de la educación, identidad.
Border identity in Chihuahua, Mexico, a journey from the 17 th to the 2ist century

\begin{abstract}
This article presents an analysis of the construction of border identity in the state of Chihuahua. Taking a tour from the seventeenth to the twenty-first century, the results of a mainly archival investigation are organized into different thematic sections. Under a critical historiographic approach and with an interpretive methodology, a trace was established through the recovery of primary documents, useful for the description and interpretation of a series of events that have impacted and redirected this border identity. As a result, different critical moments that have shaped the symbolic representation of the term border in the population of Chihuahua are shown within their context of ideological, ethnic, geographic, and cultural plurality.
\end{abstract}

Keywords: I history, historiography of education, border identity, identity 
Identité frontalière à Chihuahua, Mexique, un voyage du XVII e au XXI le siècle

\section{Résumé}

L'article suivant présente une analyse sur la construction de l'identité frontalière dans l'état de Chihuahua. Parcourant du XVIIe au XXIe siècle, les résultats d'une enquête essentiellement archivistique sont organisés en différentes sections thématiques. Dans une approche historiographique critique et avec une méthodologie interprétative, une trace a été établie à travers la récupération de documents primaires, utile pour la description et l'interprétation d'une série d'événements qui ont impacté et redirigé une série d'événements qui ont impacté et redirigé cette identité. frontière. En conséquence, différents moments critiques sont montrés qui ont façonné la représentation symbolique du terme frontière dans la population chihuahuan, dans son contexte de pluralité idéologique, ethnique, géographique et culturelle.

Mots-clés: Histoire, Historiographie de l'éducation, Identité.
Tozsamosc przygraniczna w Chihuahua, Meksyk na przestrzeni wiekow: XVI do XXI

\section{Streszczenie}

Poniższy artykuł zawiera analizę budowy tożsamości przygranicznej w stanie Chihuahua. Poczynajac od XVII do XXI wieku, wyniki badań archiwalnych są przedstawione w kilku sekcjach tematycznych. W ramach krytycznego podejścia historiograficznego i metody interpretacyjnej przebadane zostaly podstawowe dokumenty, przydatne do opisu i interpretacji serii zdarzeń, które wpłynęły i uksztaltowaly tę tożsamość. W rezultacie pokazano różne krytyczne momenty, które ukształtowały symboliczna reprezentację tozsamosci przygranicznej populacji $\mathrm{w}$ Chihuahua, to wszystko $\mathrm{w}$ ideologicznym, etnicznym, geograficznym i kulturowym kontekscie.

Slowa kluczowe: historia, historiografia oswiaty, tożsamość. 


\section{Introducción}

Bajo un método histórico crítico, con la recuperación de fuentes de archivo e interpretación de los acontecimientos históricos narrados en dichos documentos, se muestra el recorrido y contextualización de aquellos sucesos sociales, políticos y educativos en Chihuahua, que repercutieron en la conformación de su identidad. Esta concatenación de fuentes primarias, permite dar cuenta de manera descriptiva del objeto a investigar, contextualizarlo y posteriormente realizar las interpretaciones o valoraciones que, como juicios subjetivos, permiten revivir los acontecimientos; en este caso un rastreo histórico para describir e interpretar la formación de la identidad fronteriza.

La organización de los apartados responde a la necesidad de narrar aquellos acontecimientos que redirigieron la trayectoria histórica de Chihuahua, cada uno, centrado en diferentes temáticas. Se inicia con las narrativas de las fronteras que aquejaron a los nativos de esta región, cómo se fueron modificando las formas de vida de esos habitantes y las situaciones contextuales que los rodearon. Posteriormente la descripción de cómo las fronteras fueron acotando geográficamente al estado de Chihuahua por las condiciones e intereses económicos de por medio. En otro apartado se hace el análisis de las razones migratorias de sus habitantes, con base en hechos derivados de movimientos sociales y políticos del país, que en muchas ocasiones estuvieron cargados de violencia, como lo fue la invasión del ejército norteamericano, la Revolución mexicana, etc. En cada uno de estos

230 apartados, se interpreta la conformación de la identidad chihuahuense fronteriza y el papel de la educación formal en ella.

Para comenzar, y después de analizar la vasta cantidad de bibliografía que aborda estudios de frontera, se identifica la multiplicidad de aristas desde las cuales puede ser estudiada, en un inicio bastaba con la visión 
geografía y política, pero con el paso del tiempo, la frontera ha pasado a ser un objeto de estudio analizado desde diferentes disciplinas como la economía, la antropología, sociología, historia, entre otras. Siendo los límites o fronteras al interior de los individuos, aquellos subjetivos o imaginarios, los que separan territorios más complejos de conciliar.

Entonces, el concepto de frontera puede ser analizado más allá de la convencionalidad, desde diferentes perspectivas. Entre sus acepciones se incluyen las fronteras cerradas y las fronteras abiertas, las hay inexpugnables y aquellas nominales. Tal como lo expuso Sánchez (20I5) al indicar que "el territorio es una entidad espacial que sirve como instrumento de comunicación que visibiliza y hace tangibles estructuras sociales, tales como autoridad, identidad, derechos, aspiraciones, prejuicios, entre muchas otras" (p. I76).

Debido a lo anterior, se ponen de manifiesto las normatividades para transitar entre una frontera a otra, ya que existen algunas sobrecargadas de reglamentos y restricciones, que en pocas ocasiones se logran cruzar. Dentro de las fronteras intangibles se encuentran aquellas que contienen las formas de pensar desde diferentes perspectivas como las fronteras culturales, las cuales permiten cuestionar si pueden ser consideradas como un invento humano.

¿Hasta dónde la frontera es un concepto?, ¿hasta dónde es una realidad?, ¿el concepto ha evolucionado? Una simple respuesta desde el plano social es que este término se ha ido construyendo $y$ reconstruyendo desde los intereses políticos en turno; contestar desde lo económico puede centrarse en que se ha visto influido por las grandes transnacionales y fuerza de trabajo de pobres jornaleros; o bien, desde las implicaciones que conlleva la frontera para los migrantes, quienes la catalogan desde sus propios contextos culturales, lenguaje, música, creencias religiosas y existenciales. ¿Hasta dónde es un conjunto de artículos normativos y una realidad de kilómetros de 
bardas que nadie respeta?, ¿se trata solamente de una línea divisoria entre sueños y realidades, entre vida y muerte?

\section{Chihuahua sin fronteras}

Discutido lo anterior, se procede a delimitar el lugar concerniente a este texto, el estado de Chihuahua. La nomenclatura de este lugar tiene su origen en el pueblo madre Chiricagua, en ocasiones se encuentra en documentos como Chiriguahua, otras como Chirihuagua y es de estos antecedentes que se deriva su nombre actual, Chihuahua, en contra de lo que comúnmente se ha hecho creer-principalmente desde el centro de la república mexicana-, que este nombre es una interpretación desde el náhuatl, que lo traducen como piedra agujerada.

En Chihuahua coexistieron grupos originales y pobladores de la región, estaban los llamados Julimes, Tapacolmes, Cocoyomes, Chinarras, Jumanos, Salineros, Conejos, Tobosos, Conchos, Coyotes, Sumas, Chiricaguas y otros 70 grupos más, según los archivos ubicados en Parral, Chihuahua (I632-I82I) y los del municipio de Chihuahua (I709I900). Todos estos grupos poblaron en la región que comprende ahora parte de Nuevo México, Texas y Chihuahua. A estas comunidades, los colonizadores para quitarse de problemas y evitar distinguirlas a cada una, las llamaron a todas genéricamente como Apaches.

Estas agrupaciones eran nómadas, unas más que otras y no supieron de las fronteras que hoy existen, fueron grupos de personas que en

232 búsqueda de sobrevivencia seguían la huella del agua, buscaban la caza y los pastizales, según fuera la temporada. Tal como dijo Gerónimo en sus memorias "junto con el sol y el viento traspasaban montañas y planicies" (Barret, I982). 
Es posible afirmar que la representación social de frontera no existió para los pueblos aborígenes, ni en tiempo de la Colonia, cuando a manera de control se construyeron los llamados Presidios considerados como un fuerte militar en donde se resguardaban las tropas- y que de alguna manera ya delimitaban algunas regiones $o$ zonas, con la idea de establecerse como una línea de defensa, manteniendo así alejado al invasor o enemigo, sin dejarlos ingresar en cierto territorio. En este caso eran los indígenas quienes desconocían esta forma de dominio, los considerados como enemigos. Las implicaciones de esta colonización impactaron en múltiples aspectos, como las viviendas, el mercadeo, la religión y por supuesto la educación.

En el estado de Chihuahua como en otros, se instauraron dos presidios, uno de ellos ubicado en Huajoquilla, específicamente para los Tobosos y el segundo fue el presidio de San Carlos, enfocado a delimitar a los Chirrioneros, Ocomes, Sumas, Sabaneros, Texas, Cabezas, Cholomes, y los Jumanos de la región de Texas, Ojinaga, Manuel Benavides, Camargo, Aldama, hasta Chihuahua.

Después de esto, y apenas iniciada la vida independiente del país, se declaró la guerra de exterminio contra los pueblos originales durante ochenta años, de I824 a I900, llegando a el absurdo -en I849- cuando el Gobernador del estado de Chihuahua Ángel Trías, anunció la Ley de exterminio de los Apaches, publicada el 25 de mayo ante el Congreso del Estado de Chihuahua y que en el artículo $5^{\circ}$ se expresa el pago a quienes hayan matado a una persona originaria, como se muestra en las siguientes líneas:

Las cuotas de que habla el artículo tercero serán las siguientes: doscientos pesos por cada indio de armas muerto y doscientos cincuenta por cada prisionero de esta clase que sea presentado. Por cada india de cualquier edad o indio menor de catorce años, 
se pagará ciento cincuenta pesos, si se presentaren prisioneros (AHACH. [Archivo Histórico del Ayuntamiento de Chihuahua], I849).

Bastante cantidad de dinero, si se toma en cuenta que un preceptor de primeras letras -equivalente a lo que hoy son los profesores- ganaban 300 pesos al año. Esta recompensa favoreció aún más a la guerra declarada por los invasores, quienes consideraban que los Apaches no respetaban las fronteras, las cuales fueron impuestas ante la apropiación de sus tierras, prohibiéndoles a los nativos internarse en ellas; violando las costumbres ancestrales del libre tránsito que poseían los diversos grupos indígenas.

A pesar de los presidios que, a manera de frontera, se habían erigido para contenerlos y la labor de las misiones, esa guerra extendida por el territorio de Chihuahua se mantuvo con una lucha permanente en todas latitudes, la cual incluyó a diversos actores chihuahuenses. En el municipio de Parral, durante $\mathbf{1 7 7 8}$, se emitieron las órdenes por el Comandante General que indicaron la instrucción "para que se forme una partida respetable de vecinos, para que ocurra a la defensa de cualquier insulto que intenten executar los Apaches" (AHP. [Archivo Histórico de Parral], I778). Así mismo, otro personaje que también dedicó su vida a matar Apaches fue el coronel Joaquín Terrazas, primo del varias veces gobernador de Chihuahua Luis Terrazas Fuentes. Joaquín participó durante uno de los eventos lamentables que se llevaron a cabo hacia I88o, la nombrada como la batalla de Tres

234 Castillos, considerada la última de exterminio y lugar del asesinato del indio Vitorio. Acontecimiento relevante en Chihuahua que ayudó a que Vitorio, Ju y posteriormente Gerónimo se consideren como líderes de algunas tribus y un símbolo de la resistencia. 


\section{¿Cómo eran los llamados apaches?}

Se inicia por rescatar que Don Bernardo de Gálvez, en su papel de Virrey de la Nueva España -entre I785- I786- tuvo como encomienda ser el Capitán de la Compañía de Presidios del Norte durante i769- I770 y durante ese tiempo, pudo conocer en sus andanzas a diferentes grupos indígenas, además de tener la precaución de describirlos en algunos de sus reportes. A continuación, se muestra una parte del documento Instrucción del Conde de Gálvez a D. Jacobo Ugarte y Loyola, Comandante General de las Provincias Internas. México del año I786 [se respeta ortografía]:

Trae cada uno su cavallo (que por supuesto es bueno) sin mas arneses que un fuste muy ligero, herrado con cueros que preservan el casco, y que quitan con prontitud cuando llega el caso de montarlos, trayéndolos siempre del diestro hasta el dia de la función; caminan siempre de noche cuando han de atravesar algun llano, haciendo alto en las Sierras pedrosas donde no se estampa la huella para ser seguidos por el Rastro: Desde estas alturas dominan y registran los Llanos, á donde nó descienden sin ser cuidadosamente reconocidos; No hacen lumbre por el humo, ni de noche por lo que luce, evitando en sus marchas la union para no lebantar polbo, ni señalar el rastro.

En los altos, o dias de descanso és suma su vigilancia, desconfiados en estremo, son más los que belan que los que duermen, por cuya razon jamas se ben sorprendidos.

Puestos en una altura adbierten la situación de nuestros Pueblos, Haziendas, Ranchos, Cavalladas y Ganados indicandosela el humo, las lumbres, y los polvos por medio de estas señales que marcan de día, se dirijen y bajan de noche á las llanuras en busca de la presa. Así que se consideran inmediatos esconden sus 
cavallos, y dejandolos al cuidado de algunos se dividen, y cada uno por su parte se acerca lo posible para lograr el exacto y ultimo reconocimiento.

Es increíble la havilidad y destreza con que lo ejecutan, y las mañas de que se valen para su logro: Embarranse el Cuerpo y coronanse la caveza de yerva, de modo que tendidos en el suelo parecen pequeños matorrales: De este modo y arrastrándose con el mayor silencio se acercan a los Destacamentos hasta el punto de reconocer y registrar el cuerpo y ropa de los Soldados que duermen: Al mismo tiempo que están en esa silenciosa espia se dicen recíprocamente cuanto adbierten por medio de infinita variedad de vozes que contrasen exactamente, imitando el canto de las Aves nocturnas, como Lechuzas, Tecolotes, etc. Y el aullido de los Coyotes, Lobos y otros animales.

Una ves que tienen explorado el paraje a su satisfacción por medio de las mismas señales se retiran, quitan los cueros de los pies de los Caballos, montan y guardando el mismo silencio hasta la inmediación en que pueden ser sentidos, embisten con tanta furia, ímpetu y alarido que no dan tiempo de tomar las armas y ponerse en defensa á el hombre mas diestro y demas precaucion.

De estas refinadas astucias nace que tomando bien sus medidas nunca hierran el golpe, bastando diez indios para en poco mas de un minuto dejar 20 de los nuestros en el campo, y obligar a otros tantos a la fuga (AHP, I786).

En este documento es claro observar la descripción y representación que tenían los extranjeros sobre los Apaches. Mucho se les reconoce sobre sus habilidades y que llevaban gran ventaja en sus instrumentos de guerra por su ligereza, en contraste con las armas de los españoles que eran pesadas y que al cabalgar o guerrear, carecían de agilidad. Este 
es punto relevante en la conformación de la identidad, que guarda relación con la vida rural, de las personas que antecedieron y que desarrollaron habilidades con relación a una sociedad que tenían que trasladarse a largas distancias para llegar a otros poblados, extensiones desérticas poco pobladas por hombres y mujeres que vencieron las situaciones climáticas adversas. Si bien, estas acciones estuvieron encaminadas a preservar su vida, al mismo tiempo estos nativos comenzaron el arraigo en aspectos sociales, en los que se incluyen valores como la solidaridad, justicia y defensa comunal. Ciertamente los subgrupos sirvieron de soporte y de constructores de un nuevo pensamiento social, porque las necesidades de tener que recorrer los caminos con cautela, en los territorios que antes les pertenecían y ya no más, fue una situación caótica, esto significó pasar de una sensación de previa libertad a un ataque constante de muerte, situación que debió ser incomprensible.

\section{Chihuahua en medio del desierto, frontera de oro y plata}

La Nueva Vizcaya fue el primer territorio al norte de México que exploraron los españoles a mediados del siglo XVI. A través de los años, en su interior se delimitaron varias fronteras geográficas, hoy estados de la república, que circunscribieron diferentes espacios de encuentro habitable, donde se levantaban pueblos para explotar sus minerales, sobre todo plata y oro.

Alrededor de I63I montaron el corredor de San José del Parral, San Bartolomé, Santa Bárbara y San Francisco del Oro. En consecuencia, se elevó el comercio, la agricultura y la ganadería de subsistencia, actividades sincrónicas con la instauración de los poderes civiles y religiosos. Cien años más tarde se recorrió la frontera 230 kilómetros al norte, debido a los grandes descubrimientos de minerales ubicados en 
Cusihuiriachi y Santa Eulalia, agrupando doce minas. En consecuencia, llegaron oleadas de personas que se convirtieron en la fuerza de trabajo nueva, al ser insuficiente la capacidad regional con los incipientes pueblos de naturales de comunidades como San Juan Bautista, San Cristóbal de Nombre de Dios o San Gerónimo de Chinarras. Un par de décadas después de aquel periodo, en I709 se fundó San Francisco de Cuéllar -que a partir de I824 se constituyó como Chihuahua- como resultado del corrimiento de la frontera norte hacia los Estados Unidos de Norteamérica, mediando mil kilómetros, espacio que se mantuvo como el territorio de nadie por muchos años.

En este sentido y con relación a la identidad fronteriza se puede inferir que, con estos cambios, empezaba también un sentimiento de pertenencia en los chihuahuenses de aquel entonces, ya que ahí terminaba el territorio nacional, siendo ellos mismos parte de la frontera. Así como lo indicó Sánchez (2015) "la territorialidad es una dimensión de nuestra espacialidad social, la cual está íntimamente relacionada con cómo se organizan nuestras relaciones sociales, y que a su vez produce particulares arreglos y ordenamientos espaciales sobre el mismo territorio" (p. 176).

Varios acontecimientos relevantes en la historia nacional se gestaron en este lugar minero. Se inicia por mencionar que el 23 de abril de I8II, cuando arribaron presos a la ciudad de Chihuahua Miguel Hidalgo y Costilla Gallaga, junto al grupo de insurgentes que le acompañaba. La ciudad fue escogida, entre otras razones, porque estaba en medio del

238 desierto y así era imposible que otros correligionarios los rescataran. Esto se puede corroborar en la correspondencia fechada en Chihuahua, el 6 de octubre de 1795, ubicado en el Archivo de Indias, en el cual se informa que cuando le aseguraron en misiva al Comandante de las Provincias Internas de Nueva España, no había en este territorio personas que difundieran ideas "francesas... las detestables y 
perniciosas máximas de una malentendida libertad" (AHACH, I795) ni en contra de la religión católica; por consecuencia, era un lugar seguro ideológicamente y geográficamente como cárcel, donde al escaparse los insurgentes, les esperaba una muerte segura en el desierto por deshidratación, ya que tendrían que recorrer 500 kilómetros al sur para llegar a los incipientes poblados de la región de la Laguna de Mayrán hoy Torreón, Lerdo y Gómez Palacio-, si decidían hacerlo en dirección al norte, el Río Grande estaba a 370 kilómetros y la frontera con los Estados Unidos a más de I mil al ingresar por Oklahoma.

El 2I de abril de I8II se publicó el Bando -por el Ayuntamiento de Chihuahua- en el que se aprobaba el paso de visitantes para ver a los reos (Artículo primero); pero estaba prohibido formar pelotones, y quien lo hiciere sería arrestado y castigado (Artículo segundo); tampoco se permitía subirse a las azoteas (Artículo tercero); de igual manera "nadie será osado de levantar el grito para increpar a los reos, ni menos dar muestra de una imprudente compasión" así lo especificaba el (Artículo cuarto); asimismo se indicaba que "los que armaren alborotos, ruido o pleitos en la calle, serán castigados conforme a lo previsto" redactado en el (Artículo séptimo) (AHACH, I8II).

Con todos estos datos es necesario incidir en el hecho de que la estancia, juicio y fusilamiento de los insurgentes también constituyó material con el cual fue alimentada la construcción de una frontera en aquel momento inicial, ya que el territorio, ubicado en medio de la nada, fue utilizado en beneficio de aquellos que siguieron con esta lucha de poderes, de ideales y en búsqueda de la imposición social, económica y política de unos cuantos. Considerando que, en aquel momento en Chihuahua habitaba una población de 23 mil personas. 


\section{Chihuahua frontera de sangre}

Otro aspecto identitario que se considera es resultado de los múltiples enfrentamientos que se consumaron en este territorio. Uno de ellos fue el que principió como una colonización del territorio deshabitado de Texas, iniciado bajo el mando de Moses Austin en colaboración con el gobierno mexicano, y que a partir de I82I heredaría como concesión española su hijo Stephen Austin. Fue hasta I835 que algunos texanos buscaron la independencia, primero de Coahuila para constituirse en un estado más de la nación, para enseguida convertirse en una nación independiente. Por último, en el contexto expansionista de Estados Unidos decidieron apropiarse de ese y otros territorios, como lo venía haciendo desde su independencia en $\mathbf{I 7 7 6}$, cuando conformaban apenas una tercera parte de lo que es actualmente y estaba confinado a la parte este.

Los Estados Unidos de Norteamérica se fueron apoderando de diversos lugares y haciendo con ello más grande su extensión territorial. Años después del inicio de la independencia -en I803- se realizó la compra de Luisiana, siendo Napoleón Bonaparte quien la vendió a Estados Unidos de Norteamérica, territorio que incluía algunas provincias de la Nueva España. La Florida también pasó a ser parte de esta nación desde i8Io y no fue hasta i8I9 que se anexó por el tratado de Florida la primera parte de la Costa del Pacífico, luego en I845 tomó Texas y tres años después California.

Lo despoblado del territorio y las distancias enormes entre el centro de

240 México, que mantenía el control de los estados del norte, hacía todavía más difícil la conservación de la integridad del territorio nacional. Un ejemplo de ello fue en I828 cuando el inglés Robert Owen solicitó a México con el siguiente texto que enunciaba que "Ceda libremente las provincias de Texas y Coahuila" (Quintanilla, 1985, p. 54) para establecer en ella su República Idealista. Esto brinda un panorama de la noción 
existente en aquel entonces sobre esas tierras, que incidió también sobre la identidad mexicana particular de los habitantes de aquellos terruños, ya que vivían en tierras en conflicto.

En el campo educativo y relacionado con los hechos acontecidos para aquel momento, se recupera un hecho relevante que ocurrió en I843, cuando el gobernador de Chihuahua, Mariano Monterde, envió un comunicado a Laureano Muñoz y Arregui, quien fungía como Rector del Instituto Literario. En dicho documento se indicaba que necesitaba recabar "recursos con que pueda subvenir al importante objeto de auxiliar al Departamento de Nuevo México acosado por una invasión de colonos tejanos" (AHUACH, I6 de junio, I843). En esta misma carta se asentó que se repetían las circunstancias de I84I, por lo cual era imperante la cooperación para auxiliar en defensa de la integridad del territorio nacional.

En otro documento se aprecia que, durante un mes y medio después de la mencionada solicitud, se difundió un listado de personas e instituciones que debían cooperar para la guerra. Conforme a ello, se calculó un monto a cubrir de \$4I, 200 pesos entre las 407 personas obligadas a contribuir, sin figurar el nombre de algún catedrático del Instituto (AHUACH, 3I de julio, I843). Infiriendo con esta información que a los docentes no se les consideraban como personas económicamente fuertes.

Cabe mencionar que entre los nombres que sobresalen en esta lista, debido al mayor monto de su aportación al Partido de Chihuahua a nivel municipal, se encuentran: Esteban Courcier con \$ 1,947.00, Ángel Trías quien cooperó con \$ I,090 y José Cordero con \$ 892.40 pesos, pero la mayoría contribuyeron con menos de $\$$ Ioo.oo pesos, es decir entre las 407 personas debían completar \$4I,200.00 pesos que, en promedio, cada persona debió aportar \$ IOI.23 pesos. Llama la atención que entre los capitales que se gravaban estaban los Fondos de Escuela, similar a 
una caja para mantener los planteles y que eran derivados de algunos impuestos con $\$$ II 2.00 pesos y 4 reales.

A través de un pacto firmado por varias personas, entre los cuales se encontraban Antonio Jáquez, Bernardo Revilla y el rector del Instituto Literario, Don Laureano Muñoz, se asentó la oposición en contra del Gobernador Monterde, esto favoreció su derrocamiento, dejando un lugar que fue ocupado posteriormente por Ángel Trías, quien tiempo más tarde tuvo que enfrentar la invasión de algunos norteamericanos, encabezados por el coronel Doniphan.

Desde inicios de I846 se presentía que los norteamericanos invadirían más zonas del territorio de Chihuahua, por ello, precisamente el 4 de enero de ese mismo año, el Rector Muñoz recibió un comunicado del ya declarado gobernador Ángel Trías, donde se le indicaba lo siguiente:

Siendo muy probable que dentro de breve tiempo avancen a esta capital las fuerzas americanas que ocuparon la Villa del Paso, y con el objeto de proveer o poner a salvo los archivos de las oficinas públicas; dispone su Excelencia el Gobernador que todos ellos sean pesados y que comiencen a ponerse en disposición de empacarse, dando en la mayor brevedad de haberlo verificado así para agenciar los transportes que sean necesarios (AHUACH, I846).

A raíz de esto, el 3 de octubre de I846, Benito Guaspe, quien era alumno del Instituto, junto con su padre Antonio, fueron enviados por el

242 gobierno para darles instrucción militar a la infantería del municipio de Parral. Asimismo, el 22 de octubre del mismo año otro alumno llamado Mariano Terrazas hizo lo mismo, pero esa vez dirigiéndose a Santa Isabel (AHUACH, I846). Para ese momento estaba cerca la hora de entrar en batalla contra el invasor, y los estudiantes del instituto eran utilizados para un enfrentamiento militar. En este caso, la identidad y 
su relación con la educación formal se veía embestida por intereses políticos que tendrían consecuencias lamentables, así mismo se advirtió un sentido de identidad rodeado de patriotismo, al cuidar a la nación y proteger también el lugar donde radicaban, sentimiento que desencadenaron otras situaciones que involucraron a su casa de estudio, la ciudad y la nación que les rodeaba. Esta disputa concluyó con la batalla librada en Sacramento el día 28 de enero de I847 y que tuvo como resultado la derrota del ejército mexicano.

Semanas después, la entrada del ejército norteamericano a la ciudad de Chihuahua, el 2 de marzo del mismo año, ocasionó que los poderes se trasladaran a Valle de Allende y después a Guadalupe y Calvo, en ese momento y después de dichos enfrentamientos, el Lic. Laureano Muñoz sustituyó provisionalmente al Gobernador Trías, mientras este último buscaba recursos y forma de combatir al invasor, lo cual no ocurrió, porque Doniphan se retiró antes que pudieran defenderse. Se rescata de estos acontecimientos el hecho que la gubernatura se ocupó por el rector del Instituto, este acto indicó el alto prestigio que tenía ante la ciudadanía, o al menos los estrechos nexos que tuvo con el gobernador Ángel Trías.

En su estancia en Chihuahua, el ejército invasor publicó dos números del periódico llamado Anglosaxon, que se editaba tanto en inglés como en español. En esta publicación se especificó que el propósito de ingresar era la lucha por la libertad y respeto a las personas.

Fue hasta que se retiró el ejército invasor que se reanudaron las clases en el Instituto, aunque al final del curso de I846 los alumnos no presentaron los exámenes. Ante esta situación, las autoridades educativas decidieron que el 24 de diciembre de 1847 se concluyeran dichas pruebas para validar el año escolar. Todo esto ocurrió a pesar de las dificultades e interrupciones habidas, así lo hizo saber el rector en 
un comunicado que le envió al gobernador el 27 de diciembre de I847 (AHUACH, I847).

Pese al conflicto armado que acababa de ocurrir, se reanudaran las clases inmediatamente, en un afán de normalizar la vida que transcurría en el estado. Del mismo modo se iniciaron los trabajos de construcción del primer edificio patrimonio del Instituto, el 24 de noviembre de I847; ciertamente no fueron las mejores circunstancias, porque la guerra dejó en bancarrota al erario, no obstante, Don Laureano Muñoz, con su investidura de gobernador, aprovechó la coyuntura y emprendió la obra.

Después de algunos meses y aun cuando no se restañaban las heridas de la guerra, Sterling Prince entró al estado de Chihuahua de nuevo, a pesar del tratado de paz firmado, llamado Guadalupe-Hidalgo. El General Trías quien seguía en su cargo, de nuevo hizo frente al ejército invasor, en esa ocasión en el municipio de Rosales, durante la batalla librada el I6 de marzo de I848, catorce días después de haberse firmado dicho tratado del 2 de febrero. En el enfrentamiento también fue derrotado el ejército mexicano, aparte que durante la batalla murieron dos reconocidos maestros con amplia trayectoria en el Instituto Literario, uno fue Don Manuel Prado, quien inició su trabajo en junio de I845, un catedrático propietario de Medianos y Mayores que era el segundo año de latinidad -equivalente hoy a la preparatoria-; y Manuel Orona, maestro también de primeras letras (AUACH, I848).

Hasta aquí se han reconstruido una serie de acontecimientos que 244 dejaron una marca en la historia, la identidad y la sociedad chihuahuense. A Chihuahua le cercenaron una parte de su territorio y lo sintió como una amputación, herida real que no ha terminado de cicatrizar, un sentimiento particular, que no fue así en estados del sur como Zacatecas, Jalisco o Veracruz, por mencionar algunos. Fue en ese momento cuando apareció, más que allá de concepto, una realidad de 
lo que es la frontera, se convirtió en una línea utilizada para separar, dividir entre lo propio y lo de otros, entre una y otra cultura, ya que se separaron diferentes maneras de pensar, ser y actuar, incluso surgió la necesidad de conocer los distintos poderes a los cuales respetar, fueran civiles o religiosos.

Así fue como la frontera para Chihuahua se constituyó en una herida abierta en su existencia que jamás ha querido curar, al contrario, cuando parece que aminora el dolor, por cualquier pretexto vuelve abrirla, para que nunca se olvide que esa línea fue trazada con sangre. La derrota fue sensible porque participaron no solo soldados, sino también miembros de la sociedad en su categoría de voluntarios, entre los cuales se encontraban maestros y estudiantes, aunque pocos en cantidad. Así mismo, en ese momento también surgió un sentimiento de animadversión contra el centro del país, ya que las personas radicadas al sur, prometieron solidaridad, armas y soldados, quedando todo en promesas; por ello, para los chihuahuenses el sur político estuvo cargado de mentiras.

\section{Chihuahua, un refugio de pecadores}

Rápidamente las formas de vida hicieron posible un aprendizaje, la frontera podía servir como un refugio en caso de ser perseguido, bastaba con cruzar una línea para resguardarse de las autoridades de uno u otro país, quienes tenían poder dependiendo del territorio. Existen varios ejemplos de esta afirmación, uno de ellos fue el grupo de insurgentes, cuando Ignacio Allende estaba a la cabeza, después de haber sido depuesto del mando Miguel Hidalgo en la hacienda de Pabellón, cerca de Aguascalientes y ya rumbo a Zacatecas. En las declaraciones del mismo Allende, cuando estuvo preso en Chihuahua, afirmó que pretendían llegar a la frontera, pero fueron capturados antes 
de llegar a su meta, en Acatita de Baján, Coahuila. Este grupo esperaba que al llegar a Estados Unidos de Norteamérica estarían a salvo y al esperar un tiempo podrían rehacer su ejército.

De forma similar sucedió un hecho que incluyó a Benito Juárez, quien estuvo refugiado en la ciudad de Chihuahua entre I864 y i866. Este personaje apenas percibía el peligro, inmediatamente se desplazaba lo que hoy es Ciudad Juárez, ya que es la frontera del estado, razón por la cual se nombró a esta ciudad con dicho nombre.

Otro ejemplo fue cuando Francisco I. Madero y sus correligionarios desde la frontera en Ciudad Juárez emprendieron su lucha revolucionaria, no sin antes haber vivido en la ciudad de El Paso, en el país vecino, convirtiendo este lugar en una guarida desde donde fraguaron sus estrategias armadas. Similar a lo que le ocurrió a Silvestre Terrazas, un periodista crítico del porfirismo, quien acabó por refugiarse también en El Paso, desde donde continuó fustigando al régimen. Posteriormente Terrazas se convirtió en secretario del conocido Pancho Villa en tiempos de la Revolución Mexicana. Villa es otro personaje que sirve para ejemplificar lo expuesto, ya que hasta él disfrutaba de una casa ubicada en la ciudad de El Paso, en caso de que fuera necesario cruzar la frontera; aunque después del ataque a Columbus, mucho se cuidaba de acercarse a estos límites.

Tras el triunfo de la Revolución mexicana, muchos connacionales se refugiaron a lo largo de la frontera, para el caso de Chihuahua se trasladaron a El Paso, donde se quedaron a vivir o esperaron a que

246 amainara el temporal, ejemplo de esto fueron Don Luis Terrazas, Don Manuel Gameros, Don Miguel Bolaños Cacho, Don Miguel Márquez, así como cientos de ilustres chihuahuenses que tuvieron que cruzar la frontera para proteger sus vidas. La ciudad de El Paso se convirtió en un lugar de refugio, pero no solo de políticos, sino también de terratenientes quienes se vieron despojados de sus propiedades. 
Ante esta situación en El Paso se implementaron nuevos servicios de salud, educación y comercio, por lo cual otros chihuahuenses comenzaron a acudir con regularidad. Un ejemplo de esta constante movilidad, fue que varios personajes nacieron en dicha ciudad, entre ellos dos rectores de la Universidad Autónoma de Chihuahua. Uno fue Ignacio González Estavillo, el primer rector con el período I954-1955 y el otro de ellos fue José R. Miller Hermosillo, rector de la universidad entre 1973-1976. Estos sucesos reflejan la posición de algunas familias que contaban con recursos económicos suficientes y que, aunque radicaban en Chihuahua, preferían que sus hijos nacieran en El Paso, por ser el país vecino. Fueron incontables las personas que lo hicieron de esta forma, algo que se mantuvo como práctica común hasta los años noventa, unos por preferir los servicios de salud y otros buscando la nacionalidad norteamericana para sus descendientes.

En cuanto a la comercialización al interior de El Paso, se puede reducir al hecho que fue el lugar que se convirtió en la meca de los consumidores de las ciudades cercanas y al mismo tiempo en un espacio de oportunidades laborales para los residentes de Ciudad Juárez. Una historia similar para otros más, quienes en su papel de estudiantes prefirieron cursar sus estudios de secundaria, preparatoria y universidad en El Paso, aunque tuvieran que hacer largas filas para cruzar la frontera diariamente y trasladar a los hijos con dirección a la escuela. Ese punto contribuyó poderosamente a que se fraguara una cultura fronteriza, amalgamada entre mexicanos y estadounidenses. Es claro identificar que en la frontera se fue entretejiendo un híbrido con hilos de dos culturas: la anglosajona y la mexicana, reconociendo que estuvo mucho más permeada por mexicanos que por norteamericanos. 
Chihuahua como frontera cultural, científica, ideológica y económica

Por el territorio de Chihuahua han pasado con rumbo a Estados Unidos de Norteamérica no solo mexicanos, sino personas provenientes de otros países. Existen documentos que mencionan una población considerable de chinos, quienes en el periodo de I880 a I900 destacaron por ser partícipes de serie de eventos relevantes. En I88o, según los datos de León (2004) El Paso apenas tenía 736 habitantes, considerándolo como un pueblo de poca importancia. Esta situación cambió con la llegada del ferrocarril del Southern Pacific Railroud en I88I, ya que se convirtió en uno de los pasos económicos y políticos más importantes entre México y el país del norte (figura I).

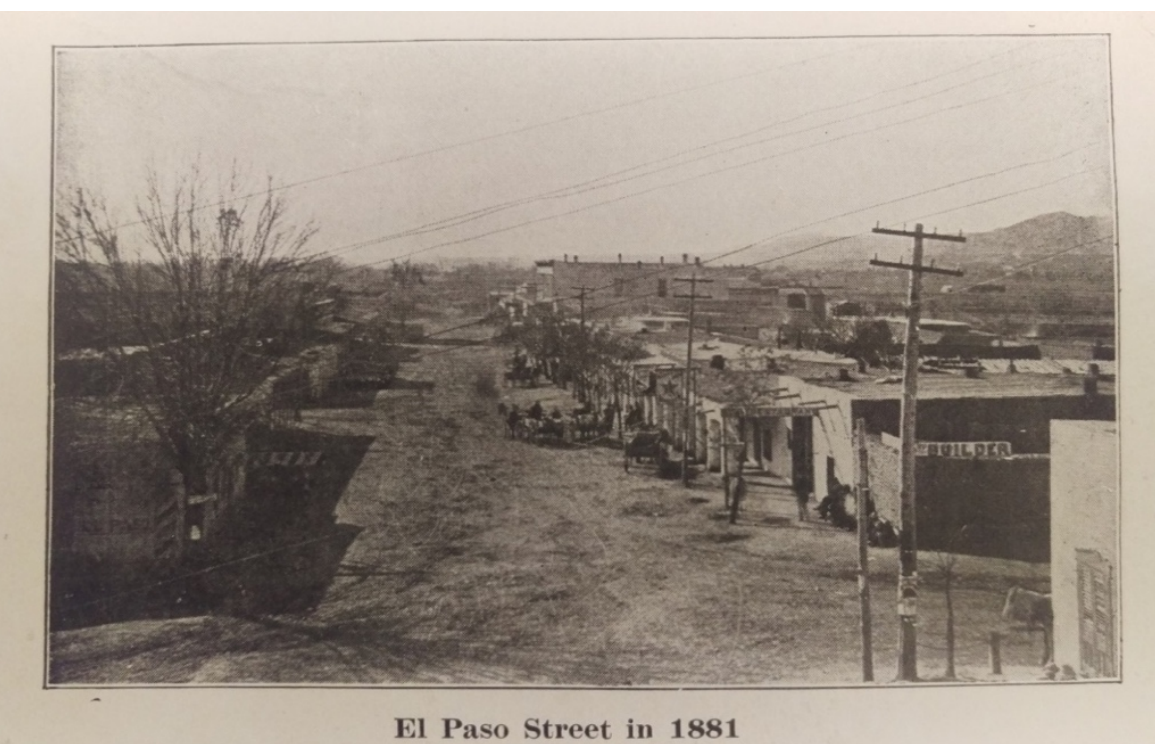

Figura I. El Paso Street in I88I. Fuente: Archivo de la Universidad de Texas en El Paso (UTEP). 
Durante aquellos momentos, los inmigrantes chinos, quienes no solo vivían en Chihuahua y fueron personajes reconocidos en tiempos de Pancho Villa, también radicaban en la región de El Paso, en donde fueron altamente discriminados entre I880 a I900. Según los informes de León (2004) los actos en contra de los chinos llegaron a tal nivel que, incluso emitieron una Ley a nivel federal, el 6 de mayo de I883, en la que se prohibía su ingreso por un lapso de diez años. Entre las consecuencias de estas agresiones, al no poder quedarse formalmente en aquel país, algunas personas de ascendencia china se quedaron en territorio mexicano, inicialmente en Chihuahua.

Las diferencias culturales de la población china se acentuaban por no dominar bien ni inglés, ni el español, de tal manera que no podían comunicarse con seguridad ante los pobladores de estas ciudades. Esta situación los condujo a aislarse, acotándose en su propia cultura y construyendo una frontera simbólica que los protegía.

Pero la frontera no se reduce a la ciudad de El Paso, otros hechos se suscitaban en la ciudad fronteriza de Ojinaga. Con el Río Bravo de por medio, esta pequeña ciudad se separa de Presidio, Texas. Dentro de este territorio desértico la mayor parte de la población ha sido la mexicana o de esta ascendencia.

En aquel lugar, también se presentaron situaciones de discriminación racial explícita, incluso había normativas diferentes, dependiendo si eran blancos o negros, diferencias que también eran aplicadas a personas de otro origen. Esto se refleja en el censo escolar realizado en I960 en el Distrito de Presidio, Texas, documentos en los cuales aparece una clasificación de los estudiantes citados como: blancos, negros, indios y otros. En este documento aparecen 4 mil 842 escolares, de los cuales 4 mil 818 eran blancos, 13 negros, 6 indios y 5 clasificados como otros (AHUTEP, 1960). 
Con estos datos se pueden afinar varias discusiones. El primer cuestionamiento es sobre el procedimiento para catalogar a los niños mexicanos, ya que algunas familias mexicanas cruzaban diariamente la frontera para llevar a sus hijos a estudiar a Presidio, con la intención de que acreditaran sus estudios básicos, además de aprender una segunda lengua. Esto fue algo rutinario, porque en aquel momento ni escolares o padres necesitaban pasaporte para ingresar al país vecino, bastaba con probar que eran residentes de Ojinaga.

Otro cuestionamiento es sobre la clasificación de blancos, infiriendo que se referían a los que tuvieran más recursos económicos. En cuanto a los afrodescendientes, llamados negros en el documento, eran pocos, en comparación de los otros grupos; estos, a pesar de ser una minoría, influyeron en la cultura de su comunidad. Por otra parte, los llamados indios, posiblemente eran descendientes del pueblo originario de esa región, conocidos como los Jumanos. En cuanto a los clasificados como otros no se descarta que hubiera algunos chinos, justificado con lo que se especificó anteriormente.

Con esto se comienzan a exponer algunas conclusiones acerca del cómo los aspectos identitarios y culturales se fueron constituyendo con la interacción de personas de origen mexicano, norteamericano, afrodescendientes, de pueblos originarios y otros más pertenecientes a grupos migrantes de diferentes países. Todas estas personas, en su cotidianidad, acumularon experiencias y construyeron fronteras ideológicas, políticas y sociales de este lugar.

250 Lo que se ha especificado a lo largo de estas páginas gira en torno al conocer cómo el estado de Chihuahua se fue poblando en torno a la frontera. Para unos se convirtió en un espacio de promisión, una opción de mejorar sus condiciones de vida, para otros expresaba diversas opciones para estudiar y con ello superar algunas expectativas, comparable al abrir una puerta de entrada hacia otra realidad posible e 
incluso soñada, preconizada como ideal. Asimismo, para otras personas la frontera tuvo un significado tan relevante, que para franquearla serían capaces hasta de arriesgar la vida, una mezcla entre la esperanza y muerte, lo único importante era cruzar el Río Bravo arriesgando todo. Así mismo, la frontera se convirtió en esperanza y maldición, un santuario, que para llegar a él era necesario primero un peregrinar, buscando el gold we trust y con ello el crucificar su existencia día a día con un trabajo sin descanso, mientras se añora a la patria ausente y con ella sus costumbres, familia, cultura y raíces.

\section{La frontera de Chihuahua se recorre 25 millas al norte a partir de 2009}

Finalmente, un periodo necesario a considerar en esta conformación de la identidad es el que comprende la ola de violencia que se desató en México con la llamada guerra contra el narco, iniciada por el gobierno federal en el 2006, siendo Felipe Calderón el presidente de la república. De manera particular, a partir del 2008 se incrementaron exponencialmente la cantidad de hechos violentos en Chihuahua, dando como resultado procesos de emigración del estado. Se consideran entre 200 y 500 mil personas quienes prefirieron buscar lugares con mayor seguridad. La mayoría de estos migrantes fueron los habitantes de Ciudad Juárez, quienes en grandes concentraciones huyeron de tal situación.

Actualmente en El Paso, como en varias ciudades estadounidenses que comparten frontera con México, es común identificar que las personas se comuniquen prioritariamente en español, que en sus calles se vendan tacos, se escucha música popular mexicana, existen colonias nuevas con mayoría connacional, además que la Universidad de Texas en el Paso y las escuelas de educación básica ahora atienden más 
personas de ascendencia mexicana, que nunca antes. Es decir, los marcos de interpretación se han reconstruido en una composición diversa, en donde la gran cantidad de mexicanos junto a ese sentimiento de orgullo de la patria, influyen al llevar sus formas de vida y concepción de la realidad hasta esta ciudad.

Es un hecho que la violencia en los últimos diez años, ha logrado que prácticamente la frontera se recorriera 25 millas al norte, bajo la premisa de tener que huir. Porque no se trata solamente de una cifra en la cual alrededor de 250 mil personas fueron asesinadas violentamente en el país; son hechos, contextos y situaciones que redireccionan a sociedades completas y que forman parte también de la conformación identitaria. Por mencionar algunos de estos quiebres, en los primeros seis meses de iniciada la independencia -toma de Guanajuato a batalla de Puente de Calderón- se contabilizaron más de Ioo mil personas muertas. En cinco años de revolución (I9II-I9I6) se contaron hasta un millón de muertos. Así que, los populares héroes nacionales son figuras llenas de sangre, quienes asesinaron y fueron asesinados, tal es el caso de Hidalgo, Morelos, Allende, Madero, Villa, Zapata, Carranza y muchos más.

Más allá de la milicia y los agentes policíacos, socialmente se han implementado diversos proyectos, entre los que resaltan estrategias de apoyo a la población joven, quienes han sido los principales protagonistas y víctimas de la violencia. Durante 2009-2019 se crearon centros de educación superior en muchos lugares y se prometieron

252 muchos más, con la firme creencia que los jóvenes deben estar en las escuelas y no en las calles. Son actos con objetivos claros, pero rebasados por las situaciones de pobreza y precariedad en la que se vive en este país. Todos los niños y jóvenes están construyendo su propia identidad, es decir cómo se perciben a sí mismos y cómo los perciben 
los demás, pero falta cuestionarse ¿Qué papel está jugando la violencia en ese contexto? y ¿cuál es el papel que juega la educación?

\section{Referencias}

AHACH. [Archivo Histórico del Ayuntamiento de Chihuahua]. (1795). Archivo de las indias. Ciudad de Chihuahua, México.

AHACH. (I8II). Bando publicado el 2 I de abril de I8II. Ciudad de Chihuahua, México.

AHACH. (I849). Ley de exterminio de los Apaches publicada por el Congreso del Estado de Chihuahua 25 de I849. Chihuahua, México.

AHP. [Archivo Histórico de Parral]. (1778). Documento número 524I-I6. Chihuahua, México.

AHP. (I786). Instrucción del Conde de Gálvez a D. Jacobo Ugarte y Loyola, Comandante General de las Provincias Internas. México. Chihuahua, México.

AHUACH. [Archivo Histórico de la Universidad Autónoma de Chihuahua]. (I843, I6 de junio). Correspondencia del I6 de junio de I843. Chihuahua, México.

AHUACH. (I843, 3I de julio). Correspondencia del 31 de julio de I843. Chihuahua, México.

AHUACH. (1846). Correspondencia. 4 de enero de I846. Chihuahua, México.

AHUACH. (I847). Correspondencia. 27 de diciembre de I847. Chihuahua, México.

AHUACH. (1848). Correspondencia. 3 de octubre de I848. Chihuahua, México.

AHUTEP. [Archivo de la Universidad de Texas en El Paso] (I88I). El Paso Street in I88I. El Paso, Texas, EUA.

AHUTEP. (1960). Censo escolar de 1960. El Paso, Texas, EUA. 
Barret, M. (1982). El Indio Jerónimo: Memorias. La Habana, Cuba: Ciencias Sociales.

León, R. (2004). Casi olvidados: Trabajadores inmigrantes no mexicanos en la ciudad de El Paso, Texas (I880-I900). Revista Avances, (56), 3-I4. Recuperado de: http://www3.uacj.mx/DGDCDC/SP/Documents/avances/Docu ments/2004/Avances\%2056.\%20Ricardo\%2oLeon.pdf

Quintanilla, S. (1985). La Educación en la Utopía Moderna, Siglo XIX. México, DF: Secretaría de Educación Pública / Dirección general de publicaciones / Ediciones el Caballito.

Sánchez, L. (2015). De territorios, límites, bordes y fronteras: una conceptualización para abordar conflictos sociales. Revista Estudios Sociales, (53),

http://dx.doi.org/I0.7440/res53.20I5.I4

Este artículo se publica bajo una licencia de Creative Commons Reconocimiento-NoComercial 4.0
Internacional, y puede ser usados gratuitamente para fines no comerciales, dando los créditos a los
autores y a la revista.

